\title{
МОДЕЛИРОВАНИЕ ОСАЖДЕНИЯ И ТРАНСФОРМАЦИИ ГИДРОГЕННЫХ МИНЕРАЛЬНЫХ ФАЗ КИСЛЫХ ШАХТНЫХ ВОД
}

\author{
Н.Ф. Фетисова \\ Горный институт УрО РАН, г. Пермь
}

\begin{abstract}
Аннотация: Гидрохимическое моделирование, основанное на термодинамических расчетах, было применено для оценки влияния кислых шахтных вод, изливающихся из штольни шахты «Таежная» ликвидированного Кизеловского угольного бассейна, на качество вод принимающих рек: Большая Гремячая и Южная Вильва, относящихся к бассейну р. Чусовой. Изложены результаты расчета индекса насыщения и моделирования осаждения основных гидрогенных минеральных фаз, характерных для кислотного дренажа, а также дана оценка возможности растворения или трансформации образованных минеральных частиц при их миграции в речном потоке.
\end{abstract}

Ключевые слова: кислотный дренаж, моделирование осаждения, растворение осадка.

\section{Введение}

Шахтные воды, содержащие высокие концентрации растворенных металлов, представляют серьезную угрозу качеству принимающих их речных вод. При смешивании кислых шахтных и нейтральных природных вод растворимость металлов значительно снижается, происходит осаждение железа и алюминия в виде аморфного охристого осадка, который покрывает дно и берега принимающих водоемов на многие километры вниз по течению $[3,5]$. Образующиеся частицы с гетерогенным составом и низкой кристалличностью удерживают за счет адсорбции и/или соосаждения многие токсичные элементы, присутствующие в шахтных водах [5]. Эти нано- и микрочастицы могут образовывать крупные агрегаты и осаждаться в русле рек, или мигрировать на большие расстояния в виде взвеси. Изменения физико-химических параметров, таких как Eh, $\mathrm{pH}$, могут приводить к растворению минеральных фаз, высвобождению токсичных элементов и их рассеиванию в водной среде [5].

Гидрохимическое моделирование, основанное на термодинамических расчетах, широко применяется в настоящее время для оценки влияния дренажных вод угольных и рудных месторождений на природные водные объекты, нахождения форм миграции элементов в водных потоках, прогноза химического состава смешиваемых вод и вторичного осадконакопления. В настоящей работе моделирование применялось для: 1) определения основных гидрогенных минеральных фаз, осаждение которых возможно в шахтном дренаже и загрязненных речных водах; 2) оценки возможности растворения взвешенных частиц образованных минеральных фаз при их миграции в речном потоке.

\section{Материалы и методы}

Объектом исследования являются кислые шахтные воды, изливающиеся из северной штольни шахты «Таежная» ликвидированного Кизеловского угольного бассейна, и принимающие их реки Большая Гремячая и Южная Вильва (рис 1).

Термодинамическое моделирование выполнялось с помощью программного кода PHREEQC с базой данных WATEQ4f. На начальном этапе исследования были рассчитаны индексы насыщения (ИН) раствора к минералам, характерным для шахтных вод. ИН представляет собой логарифм отношения произведения активностей свободных ионов к константе растворимости соединения или минерала при заданной температуре. Данный параметр характеризует недосыщенность или пересыщенность раствора по отношению к твердой фазе, т.е. указывает на потенциальную возможность растворения (при ИН < 0) или осаждения (при ИН > 0) минерала. Нулевое 


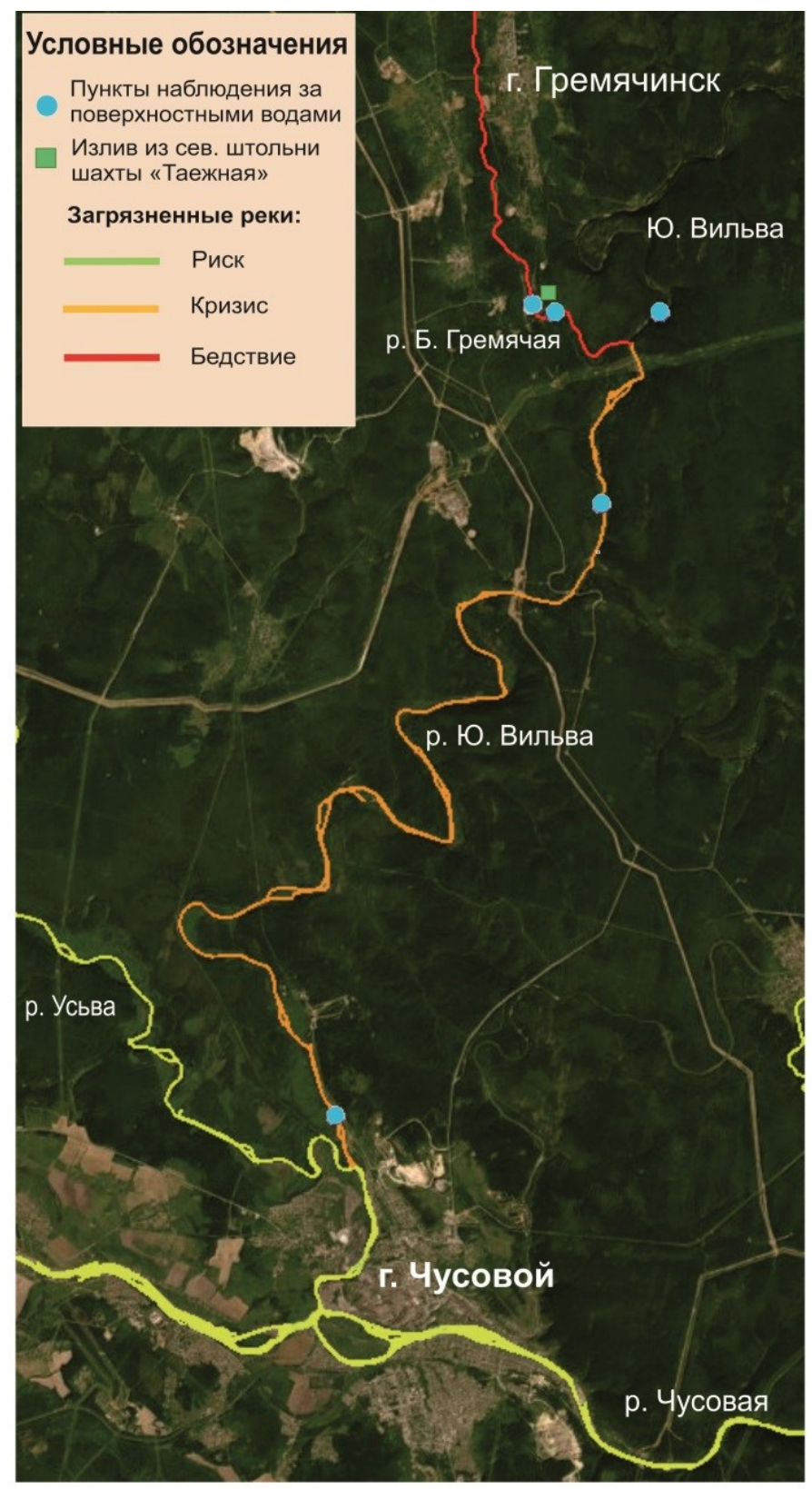

Рис. 1. Пункты наблюдения за поверхностными водами (составлено по данным 「11) значение ИН свидетельствует о том, что раствор находится в равновесии с минералом. Однако не все перенасыщенные фазы могут образовываться в условиях окружающей среды в краткосрочной перспективе. Осаждаются наиболее устойчивые соединения из числа возможных. По этой причине после определения перенасыщенных минеральных фаз было выполнено моделирование их осаждения до состояния равновесия с раствором, в результате чего были выявлены минералы, формирование которых наиболее вероятно с точки зрения термодинамики.

Согласно данным рентгеноструктурного анализа [2], среди вторичных минералов донных отложений р.Б.Гремячая ниже участка впадения шахтных вод обнаружен копиапит, общая формула которого $\mathrm{Fe}^{2+} \mathrm{Fe}^{3+}{ }_{4}\left(\mathrm{SO}_{4}\right)_{6}(\mathrm{OH})_{2} * 20 \mathrm{H}_{2} \mathrm{O}$. Однако указанный минерал не включен ни в одну из имеющихся баз данных программного кода PHREEQC.

Обзор существующей литературы на предмет нахождения качественных термодинамических данных, необходимых для включения копиапита в расчёт, не принес удовлетворительного результата. В базу данных был добавлен швертманнит - оксигидроксисульфат железа, характерный минерал охристых осадков кислых шахтных вод.

Швертманнит обычно формируется в богатых железом кислых сульфатных водах с pH от 3 до 4 и концентрацией $\mathrm{SO}_{4}{ }^{2-} \sim$ 1000-3000 мг/дм ${ }^{3}$ [6]. Наиболее подходящей для существующих условий была определена формула $\mathrm{Fe}_{8} \mathrm{O}_{8}(\mathrm{OH})_{4,4}\left(\mathrm{SO}_{4}\right)_{1,8}$ с константой растворимости $\operatorname{logKs}=10,5$ для температуры $14,6 \pm 4,7{ }^{\circ} \mathrm{C}$ [7]. Согласно исследованиям [6], швертманнит является метастабильной фазой и с течением времени преобразуется в гетит. Гетит является наиболее термодинамически стабильным минералом и всегда перенасыщен в растворах, которые также насыщены по отношению к другим охристым минералам [6]. Поскольку гетит является скорее продуктом преобразования метастабильных фаз и его появление в «свежих» осадках маловероятно, осаждение гетита не задавалось при моделировании. В качестве исходных данных для расчета использовались данные гидрохимического мониторинга Кизеловского угольного бассейна за 20016-2018 гг. [1], измеренные и рассчитанные значения $\mathrm{pH}$ и Eh. При отсутствии сведений о температуре воды использовались дан- 
ные мониторинга температурного режима рек региона, находящиеся в открытом доступе. Медианные значения химического состава вод и индексов насыщения приведены в таблице.

Химический состав вод (мг/дм³ $)$ и рассчитанный индекс насыщения

Таблица

\begin{tabular}{|c|c|c|c|c|c|}
\hline Параметр & $\begin{array}{c}\text { Б. Гремя- } \\
\text { чая выше } \\
\text { излива }\end{array}$ & $\begin{array}{c}\text { Излив из } \\
\text { шахты } \\
\text { «Таеж- } \\
\text { ная» }\end{array}$ & $\begin{array}{c}\text { Б.Гремя- } \\
\text { чая ниже } \\
\text { излива }\end{array}$ & $\begin{array}{l}\text { Ю.Вильва, } \\
\text { ниже } \\
\text { устья } \\
\text { Б. Гремя- } \\
\quad \text { чая }\end{array}$ & $\begin{array}{c}\text { Ю. } \\
\text { Вильва, } \\
\text { устье }\end{array}$ \\
\hline $\mathrm{pH}$ & 7.55 & 3.3 & 3.2 & 6.70 & 7.75 \\
\hline $\mathrm{HCO}_{3}$ & 106 & 0 & 0 & 23 & 73.5 \\
\hline $\mathrm{SO}_{4}$ & 87 & 1930 & 1015 & 19 & 28 \\
\hline $\mathrm{Cl}$ & 20 & 20 & 20 & 20 & 20 \\
\hline $\mathrm{Ca}$ & 52.7 & 161 & 96.88 & 18.85 & 24.02 \\
\hline $\mathrm{Mg}$ & 8.50 & 40 & 26.85 & 4.76 & 4.40 \\
\hline $\mathrm{Na}$ & 8.06 & 8.93 & 7.97 & 3.23 & 3.02 \\
\hline $\mathrm{K}$ & 1.64 & 18.81 & 11.50 & 0.77 & 0.65 \\
\hline $\mathrm{Al}$ & 0.19 & 32.9 & 16.98 & 0.41 & 0.13 \\
\hline $\mathrm{Fe}$ & 0.96 & 620 & 324.18 & 9.22 & 1.38 \\
\hline $\mathrm{Mn}$ & 0.076 & 6.213 & 3.43 & 0.162 & 0.038 \\
\hline $\mathrm{Li}$ & 0.011 & 0.244 & 0.149 & 0.006 & 0.003 \\
\hline $\mathrm{Zn}$ & 0.006 & 0.226 & 0.106 & 0.008 & 0.005 \\
\hline $\mathrm{Be}$ & 0.0001 & 0.024 & 0.012 & 0.0003 & 0.0001 \\
\hline $\mathrm{Pb}$ & 0.003 & 0.017 & 0.010 & 0.004 & 0.003 \\
\hline $\mathrm{Cd}$ & 0.0002 & 0.0003 & 0.0001 & 0.0001 & 0.0001 \\
\hline $\mathrm{Si}$ & 3.37 & 17.660 & 10.60 & 3.15 & 2.48 \\
\hline Кальцит $\mathrm{CaCO}_{3}$ & -0.26 & н.д. & н.д. & -2.30 & -0.40 \\
\hline Доломит $\mathrm{CaMg}\left(\mathrm{CO}_{3}\right)_{2}$ & -1.13 & н.д. & н.д. & -5.03 & -1.96 \\
\hline $\mathrm{Fe}(\mathrm{OH})_{3}($ аморф $)$ & 3.54 & 0.69 & -0.10 & 4.00 & 3.53 \\
\hline Гетит $\mathrm{FeO}(\mathrm{OH})$ & 8.87 & 5.86 & 5.30 & 9.44 & 8.98 \\
\hline $\mathrm{Al}(\mathrm{OH})_{3}($ аморф) & -0.45 & -6.50 & -6.8 & 0.56 & -0.97 \\
\hline Гиббсит $\mathrm{Al}(\mathrm{OH})_{3}$ & 2.37 & -3.63 & -3.97 & 3,36 & 1.81 \\
\hline Диаспор $\mathrm{AlO}(\mathrm{OH})$ & 3.53 & -2.49 & -2.81 & 4.54 & 2.99 \\
\hline Манганит $\mathrm{MnO}(\mathrm{OH})$ & -2.41 & -8.10 & -8.95 & -3.71 & -2.85 \\
\hline Гипс $\mathrm{CaSO}_{4} * 2 \mathrm{H}_{2} \mathrm{O}$ & -1.66 & -0.54 & -0.84 & -2.69 & -2.48 \\
\hline Ярозит-K KFe ${ }_{3}\left(\mathrm{SO}_{4}\right)_{2}(\mathrm{OH})$ & -0.12 & 6.36 & 4.78 & 1.94 & -1.78 \\
\hline Джурбанит $\mathrm{AlOHSO}_{4}$ & -3.81 & 0.00 & -0.58 & -1.71 & -5.57 \\
\hline Алунит $\mathrm{KAl}_{3}\left(\mathrm{SO}_{4}\right)_{2}(\mathrm{OH})_{6}$ & 0.14 & -2.34 & -3.99 & 4.08 & -4.24 \\
\hline Базалюминит $\mathrm{Al}_{4}(\mathrm{OH})_{10} \mathrm{SO}_{4}$ & 4.27 & -9.07 & -12.28 & 8.80 & 0.01 \\
\hline $\begin{array}{l}\text { Швертманнит } \\
\mathrm{Fe}_{8} \mathrm{O}_{8}(\mathrm{OH})_{4,4}\left(\mathrm{SO}_{4}\right)_{18}\end{array}$ & 24.2 & 12.9 & 29.6 & 33.3 & 22.6 \\
\hline Каолинит $\mathrm{Al}_{2} \mathrm{Si}_{2} \mathrm{O}_{5}(\mathrm{OH})_{4}$ & 5.39 & -4.75 & -6.60 & 7.31 & 3.46 \\
\hline $\begin{array}{l}\text { Иллит } \\
\mathrm{K}_{0.6} \mathrm{Mg}_{0.25} \mathrm{Al}_{2.3} \mathrm{Si}_{3.5} \mathrm{O}_{10}(\mathrm{OH})_{2}\end{array}$ & 2.63 & -12.31 & -15.50 & 3.27 & 0.28 \\
\hline Кол-во проб & 12 & 9 & 12 & 12 & 10 \\
\hline
\end{tabular}




\section{Результаты исследования}

Воды, изливающиеся из северной штольни шахты «Таежная», имеют сульфатножелезистый состав, высокую минерализацию (3,3-2,7 г/дм³), кислую среду (pH = 3,1$3,4)$ и высокое содержание ряда микроэлементов, превышающих ПДК Рх по Fе в тысячи, $\mathrm{Al}$ и $\mathrm{Mn}$ в сотни и по другим микроэлементам в десятки раз. По данным моделирования в зоне излива шахтных вод в осадок выпадают швертманнит и ярозит. Все отобранные здесь пробы насыщенны к $\mathrm{Fe}(\mathrm{OH})_{3}$, однако при моделировании осаждения одновременно с вышеуказанными минералами гидроксид железа не выпадает. Не насыщены шахтные воды и по $\mathrm{Al}(\mathrm{OH})_{3}$, что соответствует утверждению о том, что при $\mathrm{pH}<4,5-5$ Al ведет себя консервативно [4], т.е. остается в растворе. Однако результат противоречит опубликованным данным [2], согласно которым донные отложения на данном участке характеризуются большим количеством аморфных гидроксидов алюминия. Можно предположить, что образование $\mathrm{Al}(\mathrm{OH})_{3}$ может происходить во время паводков или под влиянием дождевых и талых вод, имеющих более высокую $\mathrm{pH}$ и содержащих растворенный $\mathrm{O}_{2}$.

Шахтные воды, поступая в р. Б. Гремячая, существенно влияют на ее состав. Гидрокарбонатно-сульфатные кальциевые воды р. Б. Гремячая ниже места впадения шахтных вод становятся сульфатно-железистыми. Наблюдается снижение концентрации компонентов примерно в 1,5-2 раза по сравнению с шахтными водами, что обусловлено как за счет разбавления, так и за счет осаждения на щелочном геохимическом барьере. $\mathrm{pH}$ смешанных вод становится ниже, чем шахтных стоков, однако концентрации загрязняющих веществ по-прежнему в тысячи, сотни и десятки раз превышают ПДК Рх. Во всех пробах, взятых из реки Б. Гремячая ниже зоны смешения, значение величины рН меньше на 0,1-0,3 единицы по сравнению с пробами шахтных вод, отобранных в один и тот же день. Выполненное моделирование показало, что в данных условиях продолжается выпадение швертманнита и ярозита. Аморфный $\mathrm{Fe}(\mathrm{OH})_{3}$ в указанных пробах либо недонасыщен, либо близок к равновесию. В процессе осаждения охристых минералов, а также трансформации их в гетит, выделяются ионы $\mathrm{H}^{+}$, что и приводит к дополнительному снижению $\mathrm{pH}$. Самопроизвольно осаждаясь, гидроксисульфаты Fе, обладая высокой удельной площадью поверхности и высокой реакционной способностью, могут сорбировать и/или соосаждать такие металлы, как $\mathrm{As}, \mathrm{Pb}, \mathrm{Cr}, \mathrm{Cu}, \mathrm{Zn}, \mathrm{Mn}, \mathrm{Cd}, \mathrm{Co}, \mathrm{Ni}$ и др. [5].

Ниже устья реки Б. Гремячая прослеживается загрязнение более крупного водотока - реки Ю. Вильва [2]. Моделирование смешивания загрязненных вод реки Б.Гремячая и чистых вод Ю.Вильвы в разных пропорциях показало, что наиболее массово на данном участке выпадает гидроксид железа. В р. Ю. Вильва в этом районе также осаждается $\mathrm{FeOH} 3$ и в значительно меньших количествах диаспор $[\mathrm{AlO}(\mathrm{OH})]$ - одна из полиморфных форм гидроксида Al. Реакция гидратации $\mathrm{Fe} 3+$ и $\mathrm{A} 13+$ протекают с выделением Н+. Несмотря на состояние пересыщения, ярозит и швертманнит на данном участке не образуются. По данным моделирования по мере осаждения $\mathrm{Fe}(\mathrm{OH}) 3$ и $\mathrm{AlO}(\mathrm{OH})$ ярозит и швертманнит становятся ненасыщенными. В данных кислотно-щелочных условиях возможно инконгруентное растворение взвешенных частиц ярозита и швертманнита с образованием соответственно гидроксида железа и гетита. Растворение этих фаз сопровождается высвобождением $\mathrm{H}+$, SO42- и сорбированных металлов в поверхностные воды.

В устье р. Вильва, где вода слабощелочная, снижается содержание $\mathrm{Fe}, \mathrm{Al}, \mathrm{Mn}$, однако концентрации сульфатов в некоторых пробах выше, чем в пробах, отобранных в этот же период выше по течению. Большая часть проб ненасыщена по ярозиту и аморфному гидроксиду Al. Взвешенные частицы ярозита здесь растворяются с выделением $\mathrm{SO}_{4}{ }^{2-}$, $\mathrm{H}^{+}$и сорбированных тяжелых металлов. Моделирование осаждения 
также показывает образование $\mathrm{Fe}(\mathrm{OH})_{3}$ и диаспора. По мере осаждения указанных фаз швертманнит становится ненасыщенным и в этих условиях также может растворяться с образованием гетита.

Приведенный пример свидетельствует, что гидрохимическое моделирование на основе термодинамических расчетов с учетом особенностей форм нахождения элементов в водных потоках и характера вторичного минералообразования позволяет осуществлять прогноз влияния сбросов шахтных вод на особенности загрязнения водоемов-приемников.

\title{
Работа выполнена при поддержке Программы ФНИ, проект № 0422-2019-0149-С-01.
}

\section{БИБЛИОГРАФИЧЕСКИЙ СПИСОК}

1. Геоэкологическая геоинформационная система Кизеловского угольного бассейна: офиц. сайт. - URL: http://kub.maps.psu.ru/(дата обращения: 20.04.2019).

2. Максимович Н.Г., Пьянков С.В. Кизеловский угольный бассейн: экологические проблемы и пути решения / ПГНИУ. - Пермь, 2018. -287 с.: ил.

3. Accornero M., Marini L., Ottonello G., Zuccolini M. The fate of major constituents and chromium and other trace elements when acid waters from the derelict Libiola mine (Italy) are mixed with stream waters // Applied Geochemistry. - 2005. - V.20. - P. 1368-1380.

4. Bigham J.M., Nordstrom D.K. Iron and aluminum hydroxysulfates from acid sulfate waters //. Sulfate minerals - crystallography, geochemistry and environmental significance. - 2000 - V. 40. - P. 351-404. - (Review in mineralogy and geochemistry). DOI: 10.2138/rmg.2000.40.7.

5. Consani S., Carbone C., Dinelli E., Baltic-Zunic T., Cutroneo L., Capello M., Salviulo G., Lucchetti G. Metal transport and remobilisation in a basin affected by acid mine drainage: the role of ochreous amorphous precipitates // Environmental Science and Pollution Research. - 2017. - V. 24, № 18. - P. 1573515747. DOI: $10.1007 / \mathrm{s} 11356-017-9209-9$.

6. Hammarstrom J.M., Seal II R.R., Meier A.L., Kornfeld J.M. Secondary sulfate minerals associated with acid drainage in the eastern US: recycling of metals and acidity in surficial environments // Chemical Geology. 2005.- V. 215, № 1-4. - P. 407-431. DOI: 10.1016/chemgeo.2004.06.053.

7. Yu J.Y., Heo B., Choi I.K., Cho J.P., Chang H.W. Apparent solubilities of schwertmannite and ferrihydrite in natural stream waters polluted by mine drainage // Geochimica et Cosmochimica Acta. - 1999. - V. 63. № 19-20. - P. 3407-3416. DOI: 10.1016/S0016-7037(99)00261-6.

\section{МЕХАНИКА ГОРНЫХ ПОРОД}

УДК 622.83

DOI:10.7242/echo.2020.2.5

\section{КАЛИБРОВКА ГЕОМЕХАНИЧЕСКОЙ МОДЕЛИ ВЗТ ГРЕМЯЧИНСКОГО МЕСТОРОЖДЕНИЯ КАЛИЙНЫХ СОЛЕЙ}

\author{
С.Ю. Лобанов \\ Горный институт УрО РАН, г. Пермь.
}

\begin{abstract}
Аннотация: Построена геомеханическая математическая модель водозащитной толщи, отражающая основные особенности геологического строения Гремячинского месторождения и проектные параметры камерной системы разработки. По результатам лабораторных экспериментальных исследований разработано параметрическое обеспечение геомеханической модели.

На основе информации о развитии процесса сдвижения земной поверхности для условий Верхнекамского и Саскачеванского калийных месторождений выполнена калибровка геомеханической модели.

Методами математического моделирования проведена предварительная оценка безопасных условий подработки ВЗТ при проектных параметрах разработки.

Исследования показали, что более предпочтительной является калибровка по данным о нарастании оседаний земной поверхности для Саскачеванского месторождения вследствие подобия горногеологических и горнотехнических условий разработки.
\end{abstract}

